\title{
Pressure and Temperature Dependence of Energy Gap in $\mathrm{SiC}$ and $\mathrm{Si}_{1-\mathrm{x}} \mathbf{G e}_{\mathrm{x}}$
}

\author{
Adnan M. Al-sheikh \\ Department of Physics $\backslash$ College of Science $\backslash$ University of Mosul \\ Mumtaz M. Hussien \\ Department of Physics $\backslash$ College of Education for Pure Science \University of Mosul \\ Siham J. Abdullah \\ Department of Radiology $\backslash$ Alnoor University College
}

(Received 27/2/2019; Accepted 15/4/2019)

\begin{abstract}
The effect of pressure on energy gap for IV-IV compound $\mathrm{SiC}$ and $\mathrm{Si}_{1-\mathrm{x}} \mathrm{Ge}_{\mathrm{x}}$ alloy have been investigated and evaluated by using Birch-Murnaghan equation of state (EOS) and Bardeen equation of state. Ambiguity in the effect of pressure and temperature on $\mathrm{E}_{\mathrm{g}}$ of different $\mathrm{SiC}$ polytypes $(3 \mathrm{C}, 4 \mathrm{H}, 6 \mathrm{H})$ have been investigated and attributed.

Variation of $\mathrm{E}_{\mathrm{g}}$ in $\mathrm{Si}_{1-\mathrm{x}} \mathrm{Ge}_{\mathrm{x}}$ evaluated and an interpretation, for it, has been suggested.
\end{abstract}

Keywords: IV-IV compounds, energy gap, high pressure, $\mathrm{Si}_{1-\mathrm{x}} \mathrm{Ge}_{\mathrm{x}}$ alloy, $\mathrm{SiC}$ pollytypes.

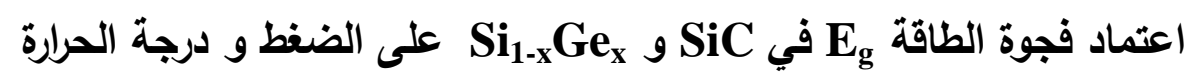

$$
\begin{aligned}
& \text { الملخص }
\end{aligned}
$$

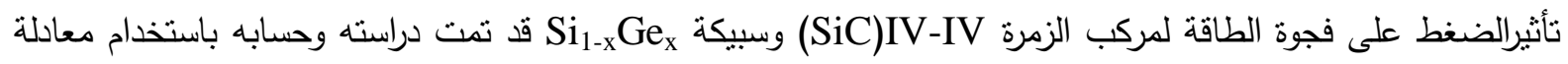

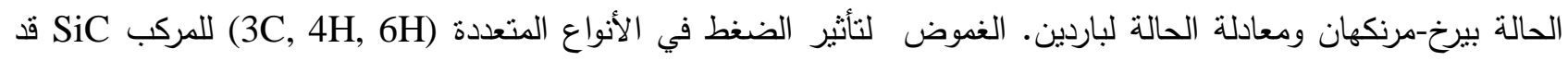

$$
\begin{aligned}
& \text { تمت دراسته وتقسيره. } \\
& \text { تغير E في سبيكة Si-x }
\end{aligned}
$$$$
\text { الكلمات الدالة: مركبات IV-IV، فجوة الطاقة، الضغط العالي، سبيكة SiC Si Si }
$$

\section{INTRODUCTION}

The electronic band structure is the significant key to understand the electrons behavior in crystalline solids, and their interaction with the lattice vibrations. It is very difficult to predict the properties of solid which contain a huge number of atoms, of the order of $10^{23}$ atoms $/ \mathrm{cm}^{3}$, It is necessary to use a suitable approximations. There are several methods to solve this problem were present in the past to calculate the band structure such as k.p, tight binding or linear combination of atomic orbital's (LCAO), pseudo-potentials, etc (Reparaz, 2008).

The electronic and optical properties has been altered due to hydrostatic pressure, these changes provides an important information on the band structure for vast variety of semiconductors (Engelbrecht et al., 1997-II).

Group IV semiconductors $\mathrm{Si}$, and Ge have the diamond structure. In this each atom is surrounded by four atoms, nearest neighbors atoms, which lies with equal distances at the corners of tetrahedron. (Otfried, 2004).

The origin of the semiconductivity of pure germanium is briefly explained using linear combination of atomic orbital's (LCAO) model as follows: 
An isolated germanium atom has four electrons in the $n=4$ outer shell which are represented by the spectroscopic notation $4 s^{2} 4 p^{2}$. In order to form bonds with other germanium atoms, one $s$ electron is promoted to $\mathrm{p}$-shell, giving the bonding electrons a $4 \mathrm{~s} 4 \mathrm{p}^{3}$ configuration. These orbital's directed to the corners of regular tetrahedron, with the result that in solid germanium, each atom is bounded to four others in tetrahedral coordination. Similarly, silicon has the electronic configuration $1 s^{2} 2 s^{2} 2 p^{6} 3 s^{2} 3 p^{2}$ simulate, in outer shell $n=3$, the configuration $3 s 3 p^{3}$.

Semiconducting phases also occur in silicon carbide $(\mathrm{SiC})$, where $\mathrm{Si}$ in outer shell has the configuration $3 \mathrm{~s} 3 \mathrm{p}^{3}$ while $C^{6}$ has the electronic configuration in outer shell $n=2,2 \mathrm{~s} 2 \mathrm{p}^{3}$. In this binary compound the differences between cubic, hexagonal and rhombohedric structure are so small, that a large number of polymorphic modifications occur. More than hundred different polytypes exist. In all polytypes every atom is surrounded by four atoms of the other species.

The group IV Silicon-Germanium random alloy differs in several respects from SiC. One of the most characteristic features of this material composition concerns bulk $\mathrm{Si}_{1-\mathrm{x}} \mathrm{Ge}_{\mathrm{x}}$ : $\mathrm{Si}$ and $\mathrm{Ge}$ are miscible over the complete range of composition (Levinshtein et al., 2001).

\section{THEORETICAL DETAILS}

The behavior of the semiconductors under pressure has been a topic of experimental and theoretical study for sometimes (Wei and Zunger,1999-II; Angilella et al., 2008).

The pressure coefficient

$$
\alpha_{P}=\frac{d E_{g}}{d P}
$$

where $\mathrm{E}_{\mathrm{g}}$ is the energy gap, $\mathrm{P}$ is the pressure.

Interband transition in a semiconductor is related to the volume deformation potential

$$
\alpha_{V}=\frac{d E_{g}}{d \ln V}
$$

Via the bulk modules $(\mathrm{B}=-\mathrm{dP} / \mathrm{d}(\ln \mathrm{V}))$ through the relation.

$$
\alpha_{P}=-\left(\frac{1}{B}\right) \alpha_{V}
$$

The pressure-volume-temperature equation of state (EOS) is fundamental to high pressure science because of its widespread use as internal pressure standard (Shim et al., 2002; Sanditov and Belomestnykh, 2011).

This work presents the effect of high pressure on energy gap by using $\alpha_{P}$ and three different EOSs which are

Murnaghan EOS (Murnaghan, 1937)

$$
\frac{V_{P}}{V_{o}}=\left(1+\frac{P B^{\prime}}{B_{s}}\right)^{\frac{-1}{B^{\prime}}}
$$

$B_{s}$ adiabatic bulk modulus, $B$ first pressure derivative of $\mathrm{B}_{\mathrm{s}}, V_{o}$ volume at atmospheric pressure, $V$ volume at pressure $\mathrm{p}$.

and (Radi et al., 2007)

$$
a_{P}=a_{o}\left(1+\frac{P B}{B_{s}}\right)^{\frac{-1}{3 B}}
$$

$a_{p}$ lattice constant at pressure $\mathrm{p}, a_{o}$ lattice constant at atmospheric pressure.

Birch-Murnaghan EOS (Birch, 1952)

$$
P_{B M}=\frac{3 B_{o}}{2}\left[\left(\frac{V}{V_{o}}\right)^{-7 / 3}-\left(\frac{V}{V_{o}}\right)^{-5 / 3}\right]\left[1+\frac{3}{4}\left(B_{o}^{\prime}-4\right)\left(\left(\frac{V}{V_{o}}\right)^{-2 / 3}-1\right)\right]
$$


Bardeen EOS(Bardeen, 1938)

$$
P_{B}=3 B_{o}\left[\left(\frac{V}{V_{o}}\right)^{-5 / 3}-\left(\frac{V}{V_{o}}\right)^{-4 / 3}\right]\left[1+\frac{3}{2}\left(B_{o}^{\prime}-3\right)\left(\left(\frac{V}{V_{o}}\right)^{-1 / 3}-1\right)\right]
$$

Where: $B_{o}$ isothermal bulk modulus at atmospheric pressure, $B_{o}^{\prime}$ first pressure derivative of $\mathrm{B}_{0}$.

Energy gap in $\mathrm{SiC}$, polytypes $(3 \mathrm{C}, 4 \mathrm{H}$, and $6 \mathrm{H})$, varies with pressure according to the fallowing relation (Levinshtein et al., 2001).

$$
E_{g}=E_{g}(0)+\alpha_{p} p
$$

Where: $\mathrm{P}$ applied pressure in $(\mathrm{Gpa}), \mathrm{E}_{\mathrm{g}}(0)$ energy gap at zero temperature.

While energy gap vary with temperature according to:

$$
E_{g}=E_{g}(0)-\frac{K T^{2}}{T+\theta}
$$

Where: $K$ temperature coefficient, $\theta$ constant, nearly equal to Debye temperature.

(Arezky et al., 2009) shows that the variation of energy gap with both temperature and pressure expressed as:

$$
E_{g}=E_{g}(0)+\alpha_{p} P-\frac{K T^{2}}{T+\theta}
$$

Variation of lattice parameter of $\mathrm{Si}_{1-\mathrm{x}} \mathrm{Ge}_{\mathrm{x}}$ system with composition can be evaluated by using the following quadratic expression (Dismukes et al., 1964).

$$
a(x)=0.002733 x^{2}+0.01992 x+0.5431(n m)
$$

(Herzog, 2000) determined variation of lattice parameter of $\mathrm{Si}_{1-\mathrm{x}} \mathrm{Ge}_{\mathrm{x}}$ system with composition by using Vergards rule.

$$
a_{S i_{1-x} G e_{x}}=a_{S i}+\left[a_{G e}-a_{S i}\right] x
$$

As a consequent of lattice parameter changes, $E_{g}$ will also be varied with composition.(Jaros,1985)expressed this variation by using the following quadric expression

$$
E_{g}=E_{g S i}+\left(E_{g G e}-E_{g S i}\right) x+c x^{2}
$$

Where: c bowing parameter equal 0.22 .

\section{COMPUTATION AND RESULTS}

\section{Variation of $\mathbf{E}_{\mathbf{g}}$ for $\mathrm{SiC}$ with pressure}

Using equation (8) with $\alpha_{p}$ data tabulated in Table-1.

Table 1: Pressure and temperature coefficients for $\mathrm{SiC}$

\begin{tabular}{|c|c|c|c|}
\hline SiC structures & $\boldsymbol{\alpha}_{p}$ & $\boldsymbol{\Theta}$ & $\boldsymbol{K}$ \\
\hline $3 \mathrm{C}$ & $-0.34 * 10^{-3}$ & 1200 & $-6.0^{*} 10^{-4}$ \\
\hline $6 \mathrm{H}$ & $-0.03 * 10^{-3}$ & 1200 & $-6.5 * 10^{-4}$ \\
\hline $4 \mathrm{H}$ & $0.08 * 10^{-3}$ & 1300 & $-6.5 * 10^{-4}$ \\
\hline
\end{tabular}


Fig. (1) shows the effect of pressure on energy gap of $\mathrm{SiC}$ in its different polytypes. Where $\mathrm{E}_{\mathrm{g}}$ for $4 \mathrm{H}-\mathrm{SiC}$ increases with pressure, while $\mathrm{E}_{\mathrm{g}}$ for $3 \mathrm{C}-\mathrm{SiC}$ and $6 \mathrm{H}-\mathrm{SiC}$ decreases with pressure as these structures have a negative $\alpha_{\mathrm{p}}$ value.

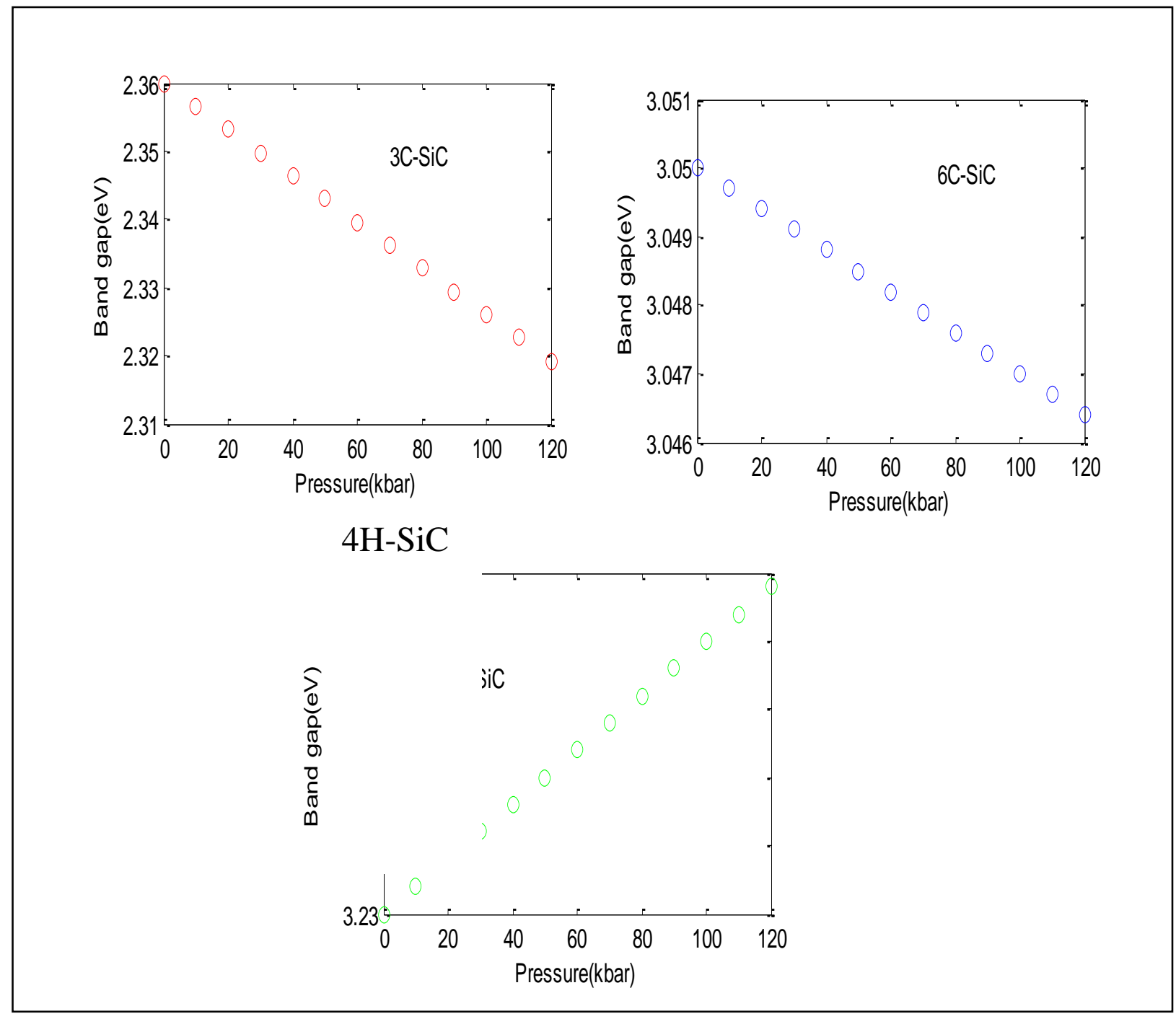

Fig. 1: The hydrostatic pressure dependences of energy gap for 3C-, $4 \mathrm{H}$ - and $6 \mathrm{H}-\mathrm{SiC}$ polytypes

\section{Variation of SiC energy gap with temperature}

On substituting $\theta$ and $\mathrm{K}$ values from (Table 1 ) and energy gap values from (Table 2 ) into eq.9, Fig. (2) shows decreasing $\mathrm{E}_{\mathrm{g}}$, for $\mathrm{SiC}$ in its different polytypes, with temperature.

Table 2: The values of energy gap for $\mathrm{SiC}$ polytypes at $(0 \mathrm{~K})$

\begin{tabular}{|c|c|}
\hline SiC structures & $\boldsymbol{E}_{\boldsymbol{g}}(\boldsymbol{e} \boldsymbol{V})$ \\
\hline $3 \mathrm{C}$ & 2.36 \\
\hline $6 \mathrm{H}$ & 3.05 \\
\hline $4 \mathrm{H}$ & 3.23 \\
\hline
\end{tabular}




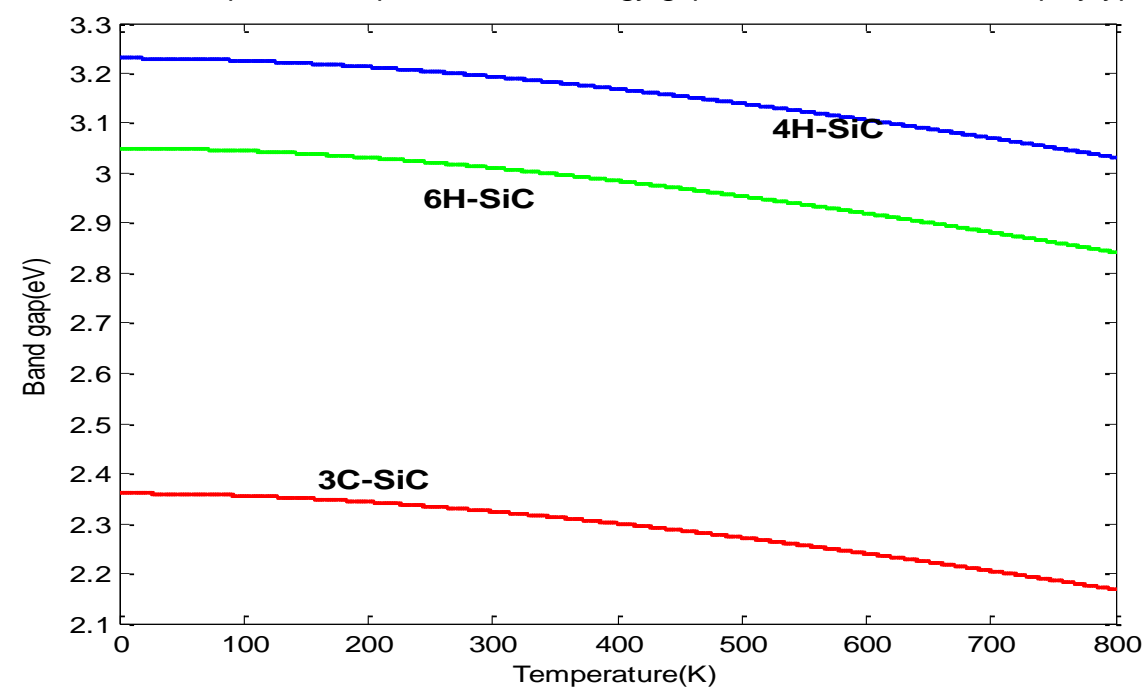

Fig. 2: Temperature dependence of energy gap for $3 \mathrm{C}-$-, $4 \mathrm{H}-$, and $6 \mathrm{H}-\mathrm{SiC}$ polytypes at atmospheric pressure

On comparing results shown in Fig. (1) and Fig. (2), it is clear that $\mathrm{E}_{\mathrm{g}}$ for $4 \mathrm{H}-\mathrm{SiC}$ structure increases with increasing pressure, Fig. (1), and decreases with raising temperature, Fig. (2), which represent, generally, an expected behavior for semiconductor martials.

But the ambiguity appear on comparing results, for 3C-SiC and 6H-SiC, shown in Fig.(1) with results shown in Fig. (2), where both figures show decreasing $\mathrm{E}_{\mathrm{g}}$ values with increasing pressure, Fig. (1), or increasing temperature, Fig. (2). In other words that $\mathrm{E}_{\mathrm{g}}$ for, $3 \mathrm{C}-\mathrm{SiC}$ and $6 \mathrm{H}-\mathrm{SiC}$, decreases by raising temperature or increasing applied pressure. In contract to the behavior of $4 \mathrm{H}-$ SiC structure.

This discrepancy between results in Fig. (1) itself, further to contradiction between results in Fig. (1) and Fig. (2), still represent a research area.

Looking to $3 \mathrm{C}, 4 \mathrm{H}$, and $6 \mathrm{H}$ structures may form a corner point in understanding this ambiguity.

$\mathrm{SiC}$ has equal parts of silicon and carbon, both of which are group IV elements. The carbon atom is situated at the center of mass of the tetragonal structure outlined by the four neighboring $\mathrm{Si}$ atoms as shown in, Fig. (3). The distance between neighboring silicon (a) or carbon atom is approximately $3.08 \AA$ forall polytypes.

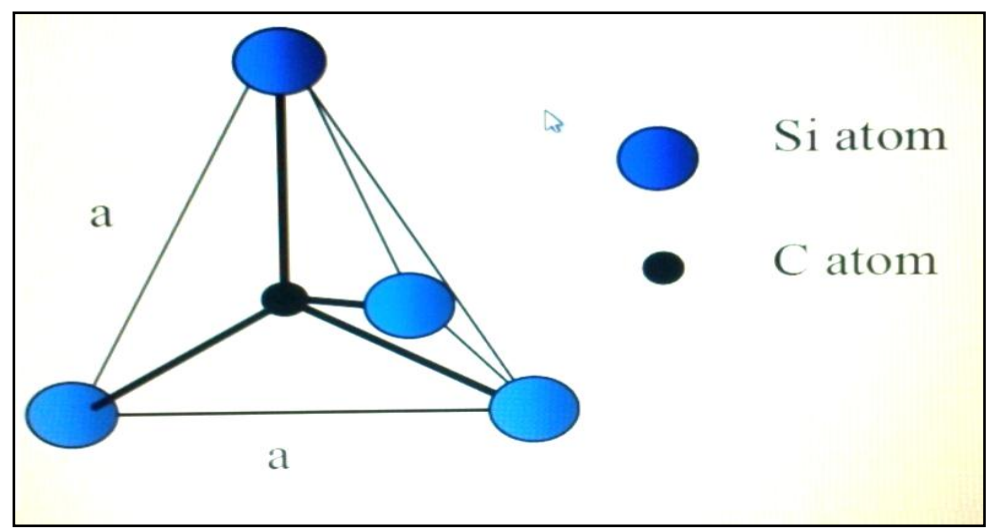

Fig. 3: The tetragonal bonding of a carbon atom with the four nearessilicon(Lee, 2002). 
The distance between the $\mathrm{C}$ atom and each of the $\mathrm{Si}$ atoms is approximately $2.52 \AA$. The height of the unit cell, called c, varies between the different polytypes. Therefore, the ratio of c/a differs from polytype to polytype. This ratio is 3.271 , and 4.908 for the $4 \mathrm{H}$, and $6 \mathrm{H} \mathrm{SiC}$ polytypes, respectively. The polytype is a variation of crystalline material in which the stacking order of planes in the unit cell is different.

Each SiC bilayer, while maintaining the tetrahedral binding scheme of the crystal, can be situated in one of three possible positions with respect to the lattice (A, B, or C), Fig. (4).

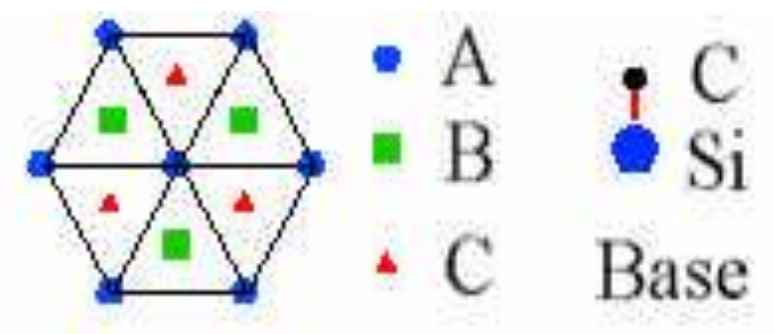

Fig. 4: The staking sequence of silicon carbide

The bonding between $\mathrm{Si}$ and $\mathrm{C}$ atoms in adjacent bilayer planes is either of a Zinc-blende (Cubic) or Wurtzite (Hexagonal) nature depending on the stacking order (Morkoc et al., 1994). As shown in Fig. (5) (Knippenberg, 1963), if the stacking is ABCABC...the cubicpolytype commonly abbreviated as $3 \mathrm{C}-\mathrm{SiC}$. While $4 \mathrm{H}-\mathrm{SiC}$ is $(\mathrm{ABCB} . .$.$) and 6 \mathrm{H}-\mathrm{SiC}$ is (ABCACB...) (Lee, 2002). These two types of $\mathrm{SiC}$ are the most common hexagonal polytypes. $4 \mathrm{H}-\mathrm{SiC}$ consists of equal amounts cubic and hexagonal bonds, while $6 \mathrm{H}-\mathrm{SiC}$ is two-thirds cubic, see (Table 3 ).

Table 3: Stacking sequences in the c-axis direction for different $\mathrm{SiC}$ polytypes

\begin{tabular}{|c|c|c|c|}
\hline & Stacking sequence & No. hexagonal & No. cubic \\
\hline $3 \mathrm{C}$ & $\mathrm{ABC}$ & 0 & 1 \\
\hline $6 \mathrm{H}$ & $\mathrm{ABCB}$ & 1 & 1 \\
\hline $4 \mathrm{H}$ & $\mathrm{ABCACB}$ & 1 & 2 \\
\hline
\end{tabular}

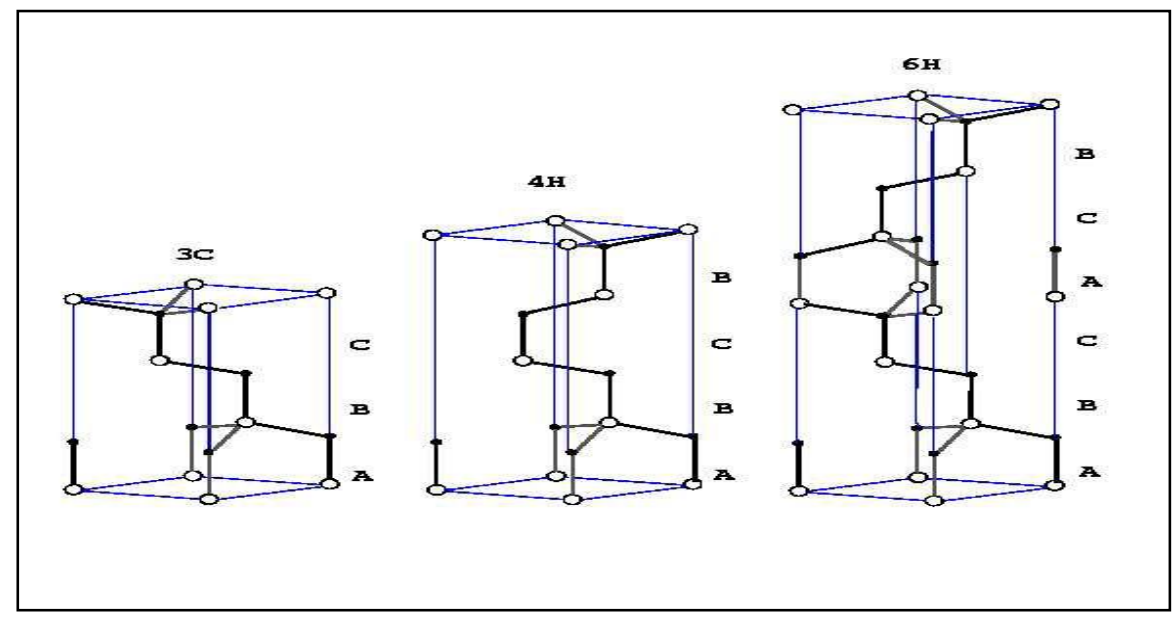

Fig. 5: The staking sequence of common $3 \mathrm{C}-, 4 \mathrm{H}-$, and $6 \mathrm{H}-\mathrm{SiC}$ 
Notifying (Table 3) and Fig. (5) indicate that 4H-SiC which have 2:1 Cubic:Hexagonal shows increases in $\mathrm{E}_{\mathrm{g}}$ with increasing pressure and decreases in $\mathrm{E}_{\mathrm{g}}$ with raising temperature, while the ambiguity appear in 3C-SiC which have Cubic structure only and $6 \mathrm{H}-\mathrm{SiC}$ Cubic-Hexagonal structure in $50 \%$, i.e. the, general, expected semiconductor behavior appear in $4 \mathrm{H}-\mathrm{SiC}$ which have hyperdized Cubic-Hexagonal structure in 2:1 sequence.

\section{Variation of $\mathrm{E}_{\mathrm{g}}$ for $\mathrm{Si}_{1-\mathrm{x}} \mathrm{Ge}_{\mathrm{x}}$ with pressure}

$\mathrm{As} \mathrm{Si}^{14}, \mathrm{Ge}^{32}$ atoms have different sizes, lattice parameters will varies with composition due to strain effect in the alloy. This change in lattice parameters might consequently cause variation in $\mathrm{E}_{\mathrm{g}}$ with composition. Furthermore electronic structures for $\mathrm{Si}: 1 \mathrm{~s}^{2} 2 \mathrm{~s}^{2} 2 \mathrm{p}^{6} 3 \mathrm{~s}^{2} 3 \mathrm{p}^{2}$ and Ge: $1 s^{2} 2 s^{2} 2 p^{6} 3 s^{2} 3 p^{6} 4 s^{2} 3 d^{10} 4 p^{2}$. Filled $3 d^{10}$ in Ge lies below $4 s$ and away from it such that it cannot interact with $4 \mathrm{~s}$. But this situation does not allow $3 \mathrm{~d}^{10}$ to be considered within the core electrons, consequently it does not take a role in construction of metallic bond, where $4 \mathrm{~s}$ electrons has the fundamental role in bond construction (Altman,1991).

On substituting $\mathrm{B}_{\mathrm{o}}$ and $B_{o}^{\prime}$ values, for $\mathrm{Si}$ and Ge from Table-IV, into eqs.6 and 7. $\left(\mathrm{V}_{\mathrm{p}} / \mathrm{V}_{\mathrm{o}}\right)$ values, for $\mathrm{Si}$ and $\mathrm{Ge}$, at different pressure has been evaluated.

Table 4: The values of lattice constant, energy gap, bulk modulus and it's first pressure derivative for $\mathrm{Si}$ and $\mathrm{Ge}$

\begin{tabular}{|c|c|c|c|c|}
\hline & $\begin{array}{c}\text { Lattice constant a } \\
(\AA)\end{array}$ & $\begin{array}{c}\text { Energy gap } \\
\mathbf{E}_{\mathbf{g}} \mathbf{( e V )}\end{array}$ & $\begin{array}{c}\text { Bulk modules } \\
\mathbf{B}_{\mathbf{o}}(\mathbf{G p a})\end{array}$ & $\begin{array}{c}\text { Firest pressure } \\
\text { derivative } \boldsymbol{B}_{\boldsymbol{o}}^{\prime}\end{array}$ \\
\hline $\mathrm{Si}$ & 5.4310 & 1.15 & 98 & 4.24 \\
\hline $\mathrm{Ge}$ & 5.6575 & 0.65 & 77.2 & 4.55 \\
\hline
\end{tabular}

as eq.5 can be rewritten in the form

$$
a_{p}=a_{o}\left(\frac{V_{p}}{V_{o}}\right)^{1 / 3}
$$

Then eq. 14 gives variation of lattice constant with pressure. On combining eqs.14 and 12 . Fig. (6) shows variation of lattice constant, forSi $i_{1-x} \mathrm{Ge}_{\mathrm{x}}$ at different compositions, with pressure.

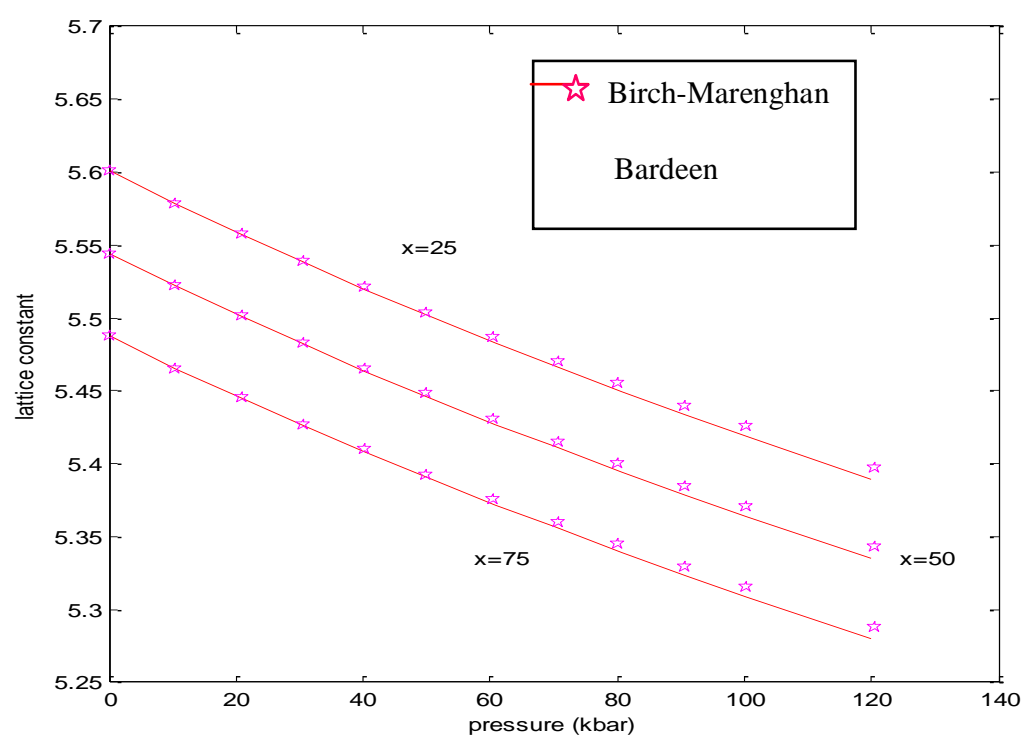

Fig. 6: Variation for, $\mathrm{Si}_{1-\mathrm{x}} \mathrm{Ge}_{\mathrm{x}}$ lattice constant with pressure at different composition, by using Birch-Muranghan and Bardeen EOSs 
Substituting $\mathrm{E}_{\mathrm{g}}$ values from (Table 4) into eq.13. Fig.(7) shows variation of $\mathrm{E}_{\mathrm{g}}$ for $\mathrm{Si}_{1-\mathrm{x}} \mathrm{Ge}_{\mathrm{x}}$ with composition.

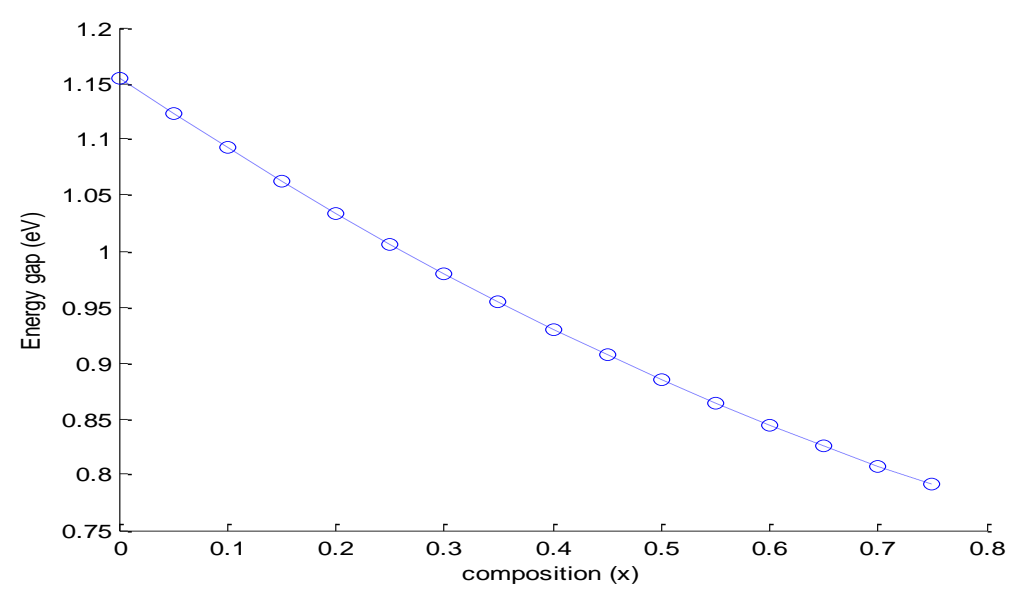

Fig. 7: Energy gap for $\mathrm{Si}_{1-\mathrm{x}} \mathrm{Ge}_{\mathrm{x}}$ at different composition at room temperature

(Adachi, 2009), express pressure coefficient for $\mathrm{Si}_{1-\mathrm{x}} \mathrm{Ge}_{\mathrm{x}}$ in the form

$$
\propto_{p}=7.8-1.6 x
$$

for $\mathrm{x}=0.5$

$$
\propto_{P}=7 * 10^{-3}
$$

On substituting $\alpha_{p}$ values into eq.8. Fig.8 show variation of $\mathrm{E}_{\mathrm{g}}$ for $\mathrm{SiGe}$ with pressure.

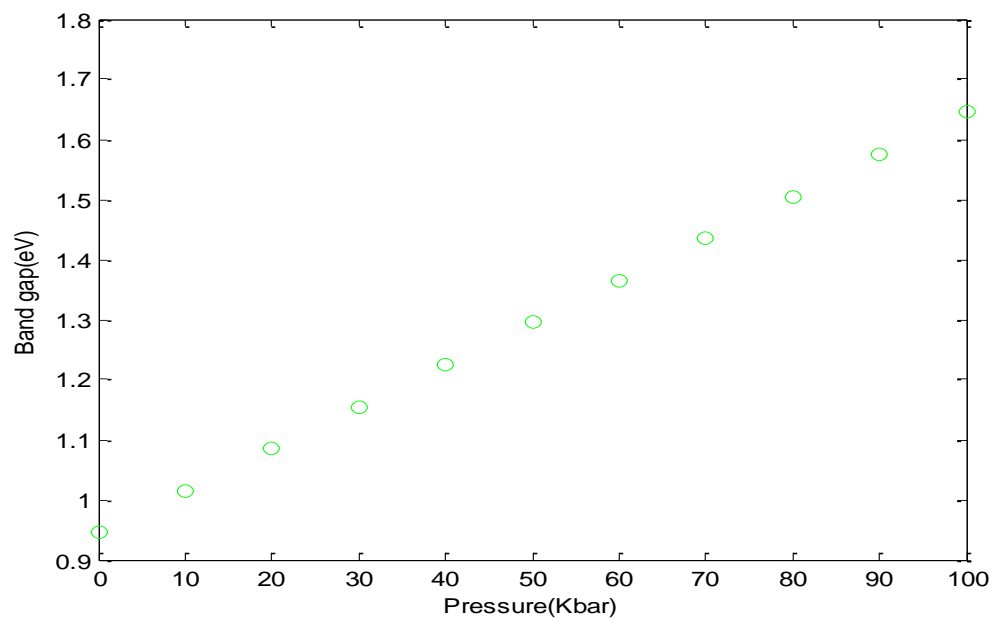

Fig. 8: Variation of $\mathrm{E}_{\mathrm{g}}$ for $\mathrm{SiGe}$ with pressure

\section{DISCUSSION}

On comparing results for $\mathrm{SiC}$ in Fig. (1) and Fig. (2) it appear that $\mathrm{E}_{\mathrm{g}}$ for $3 \mathrm{C}-\mathrm{SiC}$ and $6 \mathrm{H}-\mathrm{SiC}$ polytypes decreases with raising temperature and decreases, as well, with applied pressure, while $\mathrm{E}_{\mathrm{g}}$ for $4 \mathrm{H}-\mathrm{SiC}$ polytype decreases with raising temperature and increases with increasing applied pressure. The ambiguity in the results of $3 \mathrm{C}$ and $6 \mathrm{H}$ polytypes to have lower $\mathrm{E}_{\mathrm{g}}$ with increasing pressure or raising temperature may be attributed by the stacking sequence for $3 \mathrm{C}$ and $6 \mathrm{H}$ where there are $(0: 1$ and 1:1, hexagonal:cubic) stacking sequence. While for $4 \mathrm{H}-\mathrm{SiC}$ there is (1:2, hexagonal: cubic) stacking sequence.

For $\mathrm{Si}_{1-\mathrm{x}} \mathrm{Ge}_{\mathrm{x}}$ Fig. (7) shows that $\mathrm{E}_{\mathrm{g}}$ for this alloy decreases with composition as Ge increases. This could be interpreted by the effect of filled $3 \mathrm{~d}^{10}$ in Ge electronic configuration. While increasing $\mathrm{E}_{\mathrm{g}}$ for $\mathrm{SiGe}$ by increasing applied pressure, Fig. (8), agree, mostly, with the general properties of semiconductors. 


\section{REFERENCES}

Adachi, S. (2009). "Properties of Semiconductor Alloys: Group-IV, III-V and II-VI Semiconductors". John Wiley and Sons, Ltd ISBN, U.K.

Altmann, S.L. (1991). Band theory of solids : An introduction from the point of view of symmetry. Oxford Sci. Publications, U.K.

Angilella, G.G.N.; March, N.H.; Howard, I.A.; Pucci, R. (2008). Pressure dependence of the energy gaps in diamond-type semiconductor and their III-V analogues such as InSb. J. Phy. Conference Series. 121, 0322006.

Arezky, H.K.; Trallero-Giner, C.; Duque, C.A.; Vazquez, G.J. (2009). Optical transition in selfassembled InAs/ GaaAs quantum lens under high hydrostatic pressure. J. Appl. Phys. 105, 044308.

Bardeen, J.J. (1938). Compressibility's of the alkali metals. Chem. Phys. 6, 372.

Birch, F. (1952). Elasticity and constitution of the earth's interior. Geophys. Res. 57, 227.

Dismukes, J.P.; Ekstrom, L.; Paff, R.J. (1964). Lattice parameter and density in GermaniumSilicon Alloys. J. Phys. Chm. (USA). 68.

Engelbrecht, F.; Zeman, J.; Wellenhofer, G.; Peppermüller, C.; Hellbig, R.; Martinez, G.; Rössler, U. (1997-II). Hydrostatic pressure coefficient of the indirect gap and fine structure of the valence band of $6 \mathrm{H}-\mathrm{SiC}$. Phy. Rev. B., 56, 12

Herzog, H-J. (2000). "Crystal Structure, Lattice Parameters and Liquidus- solidus Curve of the SiGe System, Properties of Silicon Germanium and SiGe: Carbon". Edited by Erich kasper and klara lyutovich. $50 \mathrm{p}$.

Jaros, M. (1985). Electronic properties of semiconductor alloy systems. Rep. prog. Phys. 48, 10911154.

Knippenberg, W.F. (1963). Growth phenomena in Silicon Carbide. Philips Research Reports. 18, 161.

Lee, S.K. (2002). "Processing and Characterization of Silicon Carbide (6H- and 4H-SiC) Contacts for High Power and High Temperature Device Applications". Ph. D. Dissertation, Department of Microelectronics and Information Technology Device Technology Laboratory. Stockholm.

Levinshtein, M.E.; Rumyantser, S.; Shur, M.S. (2001). "Properties of Advanced Semiconductor Materials GaN, AlN, InN, BN, SiC, SiGe". Awiley-Interscience publication, John-Wiley and Sons. INC, New York.

Muranghan, F.D. (1937). Finite deformations of an elastic solid. Am. J. Math.49, 235-260.

Morkoç, H.; Strite, S.; Gao, G.B.; Lin, M.E.; Sverdlov, B.; Burns, M. (1994). Large-band-gap SiC, III-V nitride, and II-VI ZnSe-based semiconductor device technologies. J. Appl. Phys. 76, 1363.

Otfried Madelung. (2004). "Semiconductors Hand Book". $3^{\text {rd }}$ ed. Springer-Berlin-Heidelberg.

Radi, I.O.; Abdulsatter, M.A.; Abdul-lettif, M. (2007). Semiempirical LUC-INDO calculations on the effect of pressure on the electronic structure of diamond. Phys. Stat. sol.(b), 244, 4, 1304-1317.

Reparaz, J.S. (2008). Optical properties of Low-Dimensional semiconductor nanostructures under high pressure. Ph. D. Thesis department of physics university Autónoma de BarcelonaICMAB- spain.

Sanditov, D.S.; Belomestnykh, V.N. (2011). Relation between the parameters of the elasticity theory and averaged Bulk modulus of solids. Technical Physics. 56, 11, 1619-1623.

Shim, S.H.; Duffy, T.S.; Kenichi, T. (2002). Equation of state of gold and its application to the phase boundaries near $660 \mathrm{~km}$ depth in Earth's mantle. Earth and Planetary Sci. Let. (EPSL). 203,729-739

Wei,Su-Huai; Zunger, A. (1999-II). Predicted band-gap pressure coefficients of all diamond and Zinc-blende semiconductors: Chemical trends. Phys. Rev. B. 60, 8. 